\title{
Pedagogical ethics in distance education
}

\author{
Irina Valerievna Chernova $^{1^{*}}$ and Veronika Viktorovna Katermina ${ }^{2}$ \\ ${ }^{1}$ Kuban State University, Department of Theory and Practice of Translation, Krasnodar, Russia \\ ${ }^{2}$ Kuban State University, Department of English Philology, Krasnodar, Russia
}

\begin{abstract}
. 2020 was a truly revolutionary year in terms of education from the paradigm of predominantly traditional education, we had to rapidly "step" into a distance format, regardless of our desire and readiness. In 2020 two tectonic shifts happened at once: the shift from synchronous offline classes (education) to synchronous online and then from synchronous formats to asynchronous and mixed. In addition to issues related to the technical support of the educational process, the issue related to the development of new professional and pedagogical principles and rules that would contribute to the highly moral behavior and activities of the teacher in creating a comfortable environment for all participants of distance learning process, emphasizing that ethical requirements must reflect the relationship between teachers and learners. We conducted a research aimed at revealing the principles and values the teachers consider crucial to follow when conducting online classes, the skills they think they need master in order to raise the level of their professional expertise, improve the effectiveness of teaching and learning processes, and make their students self-confident and independent. The results of the survey can be used in designing special courses devoted to professional or pedagogical ethics in online learning.
\end{abstract}

Keywords: distance learning, digitalization, pedagogical ethics

\section{Introduction}

The research centers around the issue of pedagogical ethics - the concept the importance of which has reestablished itself in a new era of education, the concept that plays a significant role in teaching and learning processes promoting the effective relationship between educators and learners cemented by mutual trust and respect.

When conducting the research we were inspired by the works of Cleveland-Innes, Garrison, Jiang, Khrapov, Baeva, Mironowicz, Schretzenmayr, Mohsen, Moore, Pertti, Polat, Salta, Paschalidou, Tsetseri, Koulougliotis, Strekalova, Verbitsky [1-12] devoted to the attempts, failures and successes of distance learning.

For us, it is of interest to study distance education in the aspect of the peculiarities of communication between a teacher and a student. Zinkovskaya, Katermina, and Plaksin say that "distance learning is a special form of interaction between a teacher and a student using various means of modern information technologies when the student has the opportunity to

*Corresponding author: irochka.chernova00@mail.ru 
receive the required amount of knowledge as a part of the curriculum and perform the teacher's tasks not only in real-time but also asynchronously while monitoring the implementation of educational assignments and feedback occur on a regular basis using various technical means asynchronously" [13]. Ippolitova defines pedagogical communication as "the interaction of a teacher and students, providing motivation, efficiency, creativity and educational effect of joint communicative activity" [14]. The purpose of distance learning is to "develop a competent and successful online learner who displays strong academic self-concept, fluency in the use of online learning technologies, interpersonal and communication skills, understanding and valuing interaction and collaborative learning, an internal locus of control, self-directed learning skills, and a need for affiliation" [15]. Of course, these attitudes and competencies do not develop on their own; they must be nurtured with the guidance of competent online educators who design pedagogically sound activities, aimed at creating in students a sense of belonging, well-being, and a feel of expertise.

\section{Methodology}

We conducted a survey among the teachers (50 people) of Kuban State University whose teaching experience was less than 5 years, from 5 to 15 years and more than 15 years. We designed a questionnaire and asked the university teachers about personal and professional qualities they consider important to develop in themselves when teaching online, the methods of improving motivation that they use in their online practice, the necessity to talk with students on topics not related to mastering the discipline to raise the level of students' moral, cultural, scientific development, the difficulties they come across when teaching online.

By pedagogical ethics in distance education, we understand moral values and beliefs that educators follow to make their students feel confident in their strengths and capabilities. These are the principles that constitute the professional competence of a teacher, his/her ability to be fair and unbiased, tolerant, and open-minded in an open online space; to be able to motivate, monitor, evaluate, praise, give competent feedback to their students and at the same time, which is very important for online learning, provide enough independence and autonomy.

\section{$3 \quad$ Results}

Today, the professional pedagogical community puts forward requirements for the teacher's personal qualities which are inseparable from his or her professional competencies. An indisputable fact is that the spiritual and moral development of the teacher himself/herself is a powerful lever of the processes of self-development and continuous spiritual and moral self-improvement of students. The results of the questionnaire survey of teachers are presented in Table 1.

Table 1. Survey of teachers.

\begin{tabular}{|l|c|c|}
\hline \multicolumn{1}{|c|}{ Kuban State University } & Research & Date / / \\
\hline Question & $\begin{array}{c}\text { Number of } \\
\text { teachers }\end{array}$ & $\%$ of teachers \\
\hline 1 Teaching experience & 13 & 26 \\
\hline$<5$ & 27 & 54 \\
\hline $5-15$ & \multicolumn{3}{|l|}{} \\
\hline
\end{tabular}




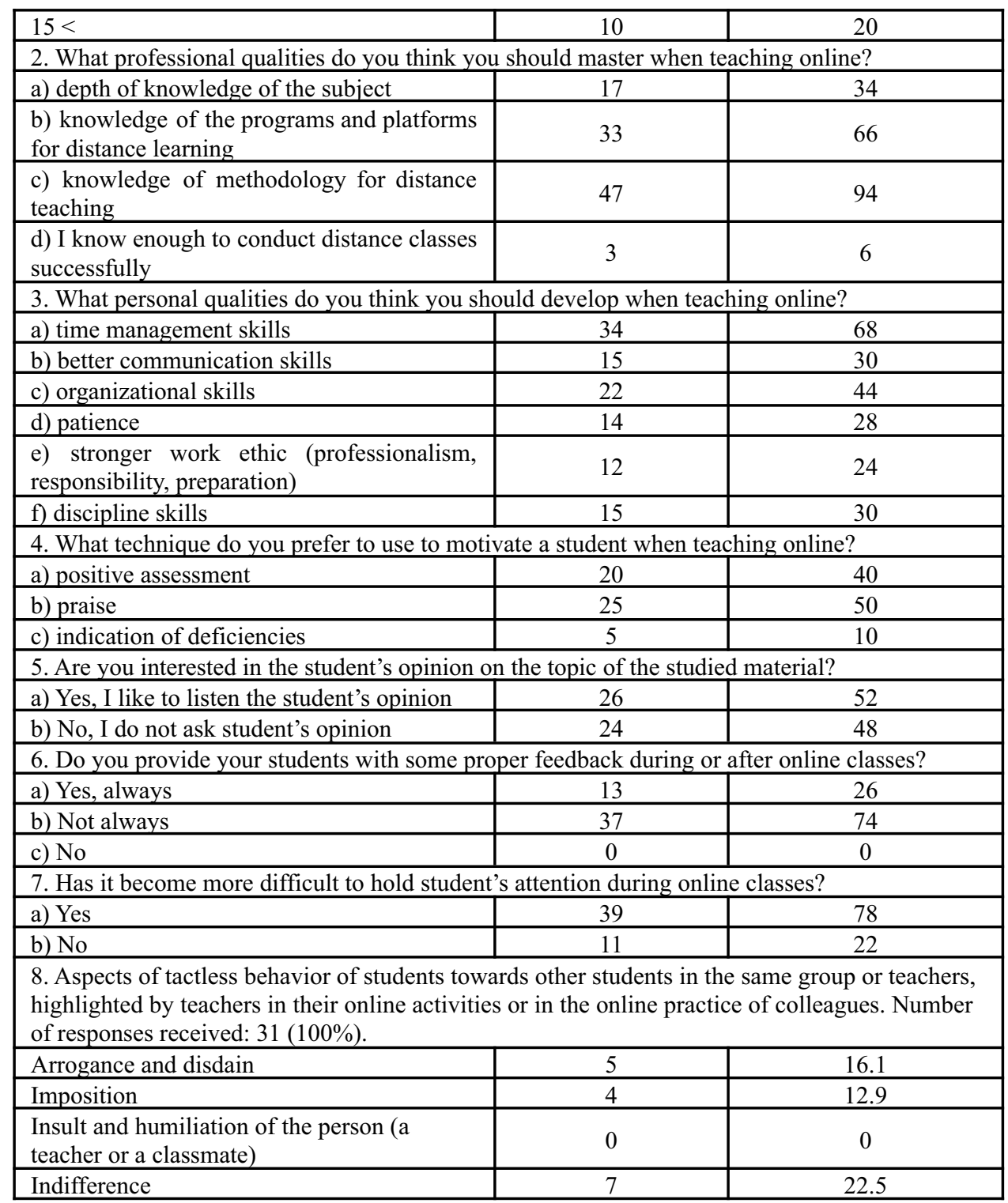

During "pandemic online teaching" university teachers realized their extreme need for continuous professional development. Most of the educators acknowledged that they did not use online educational platforms to organize their courses. Unfortunately, very useful programs and apps like WordWall.net, Mentimeter, Quizlet, Google Forms, etc., which can make the classrooms more interactive, motivating, dynamic and engaging still remain underused. Moreover, the educators also understood that they must improve their level of expertise in the methodology of online teaching.

\section{Discussion}

Based on the results of this study, we can draw the following conclusions. 
Only $34 \%$ of teachers indicated that they are ready to develop the depth of knowledge of the subject, which means their desire to improve the level of their professional training, qualification in order to give proper knowledge to their students. These are mostly teachers who have less than 10 years of teaching practice. In this regard, distance learning is the best opportunity for educators to improve their skill level by being able to participate in webinars, national and international forums and conferences with colleagues, access to which offline is difficult for financial reasons and due to workload. Young educators also highlighted that they would like to enroll in some online courses on time management and professional skills development to improve their efficiency and work-life balance, to spend less time on lesson planning and preparation but to be more productive and do more in less time. The older generation of teachers with the experience of more than 15 years is more likely to expand their knowledge of existing online platforms for distance learning and methodology of online teaching.

Such an important aspect of online teaching as creating motivation for learning is seen by most teachers through encouragement, praise and positive assessment. However, we also see that $10 \%$ of teachers still choose the tactic of pointing out the shortcomings. This technique, based on our practice, can really turn out to be effective but with respect to an absolutely small number of students who have a certain psychological portrait. In order to motivate their students, teachers should lead the group creating a sense of well-being, discovering common ground, helping to set goals, promoting affiliation. Teachers who work online must avoid routine passive exercises, they should try and make the listeners become active participants of the activities offered. Student's brain resists everything that is routine, and the stronger the resistance, the worse the learning. Unfortunately, not all students have the same attention span or the same level of discipline concerning their attitudes and behaviors especially when it comes to online classes. Teachers have to be patient and remember that monitoring students' involvement and attention is an unavoidable part of teaching.

About $52 \%$ of teachers are interested in a student's opinion on the subject of the studied material. This indicator shows us that most teachers consider the learning process to be reciprocal, they strive to bring the taught material closer to the needs and requirements of students, to make the learning process more flexible which reflects one of the main advantages of distance learning. Those teachers who do not ask for student's opinion then commented that they actually used to ask their students but most of their learners answered that they fully trust their educators and have no objections to the chosen educational material.

To boost their online teaching educators should collect, review and give proper feedback based on student performance. They should regularly monitor and check students' progress. This is, in our opinion, a very powerful tool to improve teaching and learning online and to help learners grow in self-regulated learning, independence and autonomy. Proper feedback is feedback, which is clear, explanatory, timely, non-judgmental, personal, both positive and negative. It is important and useful to give negative feedback along with the positive one because when a student receives positive feedback only, he/she may develop the so called path dependence.

In the survey, we also included a question regarding the aspects of unethical behavior of students identified by teachers in their activities. Some learners showed imposition and behaved more arrogantly and disdainfully during online classes compared to how they usually behave in traditional classrooms. It is obvious that students' behavior depends mostly on their individual character not the form of the learning process. But, it was noticed that some students begin to feel more frivolous during online classes, show their 
indifference towards the studying material or work of a teacher. Fortunately, no teacher experienced any form or acts of humiliation or insult.

\section{Conclusion}

It is known that in the educational activity students largely rely on and follow an example of their teacher. In the formation of students' opinions about teachers, the most important wheel is played by both the knowledge of the subject and the competence of the teacher as well as such qualities as fairness, friendliness, willingness to help in mastering the discipline, active participation in the life of the student collective. The style of distance pedagogical communication has some peculiarities concerning the fact that, considering the remoteness of the teacher and students, the question of the need, first of all, to teach students to learn, to develop in them the skills of independence and discipline, to motivate students for educational and scientific activities becomes more acute. The results of the survey bring us to the conclusion that the ethical side of distance learning is embodied in a personality of a teacher who follows the principles of strong work ethics, who possesses good time management, communication, discipline and organizational skills, who knows the methodology of online teaching, online educational platforms and can use them in his/her practice, and who is also patient, empathic, friendly and fair.

\section{References}

1. M.F. Cleveland-Innes, D.R. Garrison (eds) An Introduction to Distance Education:

Understanding Teaching and Learning in a New Era (Routledge, 2020).

https://doi.org/10.4324/9781315166896

2. W. Jiang, Dist Edu, 38(1), 84-105 (2017).

https://doi.org/10.1080/01587919.2017.1299564

3. S.A. Khrapov, L.V. Baeva, Cognitive Risks of Education Digitalization: Crisis Transformation of Student Consciousness and the Problem of Forming Safe Communicative-Educational Environment, in Proceedings of the International Scientific Conference "Digitalization of Education: History, Trends and Prospects" (DETP 2020) (2020). https://doi.org/10.2991/assehr.k.200509.001

4. S. Manijeh, Int J Res Engl Edu, 4(1), 80-88 (2019). https://doi.org/10.29252/ijree.4.1.80

5. I. Mironowicz, M. Schretzenmayr, Plan Rev, 56(4), 107-121 (2020). https://doi.org/10.1080/02513625.2020.1906064

6. F.F. Mohsen, Proc - Soc Behav Sci, 46, 890-894 (2012). https://doi.org/10.1016/j.sbspro.2012.05.218

7. M.G. Moore, The Theory of Transactional Distance, in M.G. Moore, W.C. Diehl (eds), Handbook of Distance Education (Routledge, 2018). https://doi.org/10.4324/9781315296135-4

8. J.K. Pertti, Int J Theory Prac, 9,2003(1), 9-23 (2010). https://doi.org/10.1076/edre.9.1.9.13544

9. E.S. Polat, Pedagogicheskie tekhnologii distancionnogo obucheniya: uchebnoe posobie dlya vuzov [Pedagogical technologies of distance learning: a textbook for universities] (YUrajt, Moscow, 2020) 
10. K. Salta, K. Paschalidou, M. Tsetseri, D. Koulougliotis, Sci Edu (2021). https://doi.org/10.1007/s11191-021-00234-X

11. N.B. Strekalova, Bul Samara Univ. Hist, Pedag, Philol, 25(2), 84-88 (2019). https://doi.org/10.18287/2542-0445-2019-25-2-84-88

12. A.A. Verbitsky, Homo Cyberus, 1(6), 20 (2019)

13. A.V. Zinkovskaya, V.V. Katermina, V.A. Plaksin, "Corona-Trigger”: Optimization Possibilities of the Teaching Algorithm in Higher Education Institutions", in Proceedings of the Research Technologies of Pandemic Coronavirus Impact (RTCOV 2020) Advances in Social Science, Education and Humanities Research, 486, 39-43 (2020). https://doi.org/10.2991/assehr.k.201105.008

14. N.A. Ippolitova, Pedagogicheskaya ritorika v voprosah i otvetah [Pedagogical rhetoric in questions and answers] (MPGU, Moscow, 2011)

15. V. Russell, K. Murphy-Judy, Teaching Language Online: A Guide to Designing, Developing, and Delivering Online, Blended, and Flipped Language Courses (Routledge, 2020). https://doi.org/10.4324/9780429426483 